\title{
Anti-obesity Activity of Ethanol Extract from Bitter Melon in Mice Fed High-Fat Diet
}

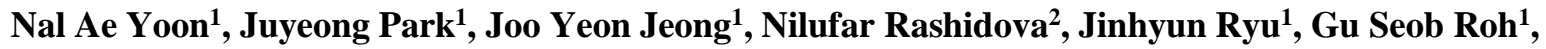 \\ Hyun Joon Kim , Gyeong Jae Cho', Wan Sung Choi ${ }^{1}$, Dong Hoon Lee', and ‘Sang Soo Kang ${ }^{1}$ \\ ${ }^{I}$ Dept. of Anatomy \& Convergence Medical Science, In-stitute of Health Sciences, College of Medicine, \\ Gyeong-sang National University, Jinju 52727, Korea \\ ${ }^{2}$ Tashkent Medical Academy, Farabi Street 2, Tashkent 700109, Uzbekistan
}

\begin{abstract}
In many cases, obesity is associated with metabolic disorders. Recently, natural compounds that may be beneficial for improving obesity have received increasing attention. Bitter melon has received attention as a diabetes treatment. NAD ${ }^{+}$-dependent deacetylase (Sirtuin 1, SIRT1) has emerged as a novel therapeutic target for metabolic diseases. In this study, ethanol extract of bitter melon (BME) suppressed adipocyte differentiation and significantly increased the expression of SIRT1 in fully differentiated 3T3-L1 cells. Moreover, it enhanced the activation of AMP-activated protein kinase (AMPK). In high-fat diet (HFD)-fed induced-obesity mice, BME suppressed HFD-induced increases in body weight and white adipose tissue (WAT) weight. BME also increased the expression of SIRT1 and suppressed peroxisome proliferator-activated receptor and sterol regulatory element binding protein 1 expressions of WAT from HFD-fed mice. These findings suggest that BME prevents obesity by activating the SIRT1 and AMPK pathway and that it may be a useful dietary supplement for preventing obesity.
\end{abstract}

Key words : Bitter melon, High-fat diet, Obesity, 3T3-L1, Sirtuin 1

\section{INTRODUCTION}

Obesity is characterized by excessive body weight and abnormal body fat accumulation and is becoming a serious global health problem (Kopelman, 2000; Chang et al., 2017). It is associated with a chronic inflammatory state and other metabolic disorders such as hyperlipidemia, type 2 diabetes, cardiovascular diseases and cancer (Keller \& Lemberg, 2003; Pi-Sunyer, 2009; Han \& Lean, 2016). It is associated with an imbalance between energy intake and expenditure and the subsequent excess accumulation and adipogenesis of adipose tissue (Jung \& Choi, 2014). Adipogenesis is the process by which an undifferentiated preadipocyte is converted into a fully differentiated adipocyte and plays a key role in fat mass growth and the regulation of adipogenesis (Kim et al., 2012; Park et al., 2012; Yang \& Kim 2015).

Sirtuins, a family of NAD+-dependent deacetylases, have recently emerged as novel therapeutic targets for metabolic diseases. Sirtuin (silent mating type information regulation 2 homolog) 1 (SIRT1) is thought to influence diverse biological processes via the direct deacetylation of peroxi-

\footnotetext{
Manuscript received April 27, 2019, Received in revised form May 10, 2019, Accepted May 18, 2019

${ }^{\dagger}$ Corresponding Author : Sang Soo Kang, Department of Anatomy \& Convergence Medical Science, College of Medicine, Gyeongsang National University, Jinju 52727, Korea. Tel: +82-55-772-8033, Fax: +82-55-772-8039, E-mail: kangss@ gnu.ac.kr

This is an Open Access article distributed under the terms of the Creative Commons Attribution Non-Commercial License (http:// creative-commons.org/licenses/by-nc/3.0) which permits unrestricted non-commercial use, distribution, and reproduction in any medium, provided the original work is properly cited.
} 
some proliferator-activated receptor $\gamma(\operatorname{PPAR} \gamma)$, coactivator- $1 \alpha$, forkhead box $\mathrm{O} 1$, and $\mathrm{p} 53$ and via the indirect activation of AMP-activated protein kinase (AMPK) signaling, by stimulating fat utilization to prevent diet-induced obesity and its associated disorders (Ye et al., 2017). Recently, natural compounds that may be beneficial for reducing the pathogenesis of obesity and metabolic syndrome have been investigated (Graf et al., 2010; HasaniRanjbar et al., 2013).

Bitter melon (Momordica charantia L., Cucurbitaceae) grows in many countries of Asia. Its fruit, fruit juice and dried powder preparations have been widely used as traditional medicationsto lowerthe blood glucose levels and obesity andto inhibit the proliferation of various cancer cells by inducing apoptosis (Ray et al., 2010; Fuanchan et al., 2011; Ru et al., 2011). Recently, the ethanol extract of bitter melon (BME) was shown to control pancreatic beta cells in streptozotocin-induced type 2 diabetic rats (Hafizur et al., 2011). We also published a paper that BME had antidiabetic effect on the high-fat diet (HFD)-fed mice (Yoon et al., 2017). However, how BME interacts with specific targets in the various pathways involved in obesity and metabolic disorders is unknown.

Therefore, in this study, we investigated the potential beneficial effects of BME by using the pre-adipocyte 3T3L1 cell system and an animal model.

\section{MATERIALS AND METHODS}

\section{Preparation of BME}

Preparation of BME was described in a previous study (Yoon et al., 2017). Briefly, BME was manufactured and verified by Daeho Corporation Co., Ltd. (Hwaseong, Korea). All the BME used in present study was grown in Hamyang (Cheonryung Foods Co., Ltd., Hamyang, Korea). The dried unripe fruit was shattered and extracted by heating twice at $70{ }^{\circ} \mathrm{C}$ (4 h and $2 \mathrm{~h}$ ) with $70 \%$ ethanol. The extract was then filtered and concentrated (Busung Tech, Ansung,
Korea) to $15-20$ degrees Brix at $65^{\circ} \mathrm{C}$. The concentrated extract was spray dried (Mehyun Engineering, Anyang, Korea) at an inlet temperature of $175 \pm 10^{\circ} \mathrm{C}$ and an outlet temperature of $80 \pm 5^{\circ} \mathrm{C}$, and then dextrin (49\%) and lecithin $(1 \%)$ were added. The extraction yield was approximately $34 \%(w / w)$.

\section{Cell culture}

3T3-L1 pre-adipocyte cells, purchased from ATCC (ATCC CL-173, Manassas, VA, USA), were maintained as preadipocytes in 90\% Dulbecco's Modified Eagle's Medium (DMEM) supplemented with 10\% FBS (FCS; HyClone, Logan, UT) and $0.1 \%$ Pen-Strep (referred to in the text as growth medium). The 3T3-L1 pre-adipocytes were always passaged before the cultures reached $70 \%$ confluence. To induce the differentiation of the 3T3-L1 pre-adipocytes to adipocytes, we employed procedures recommended by the ATCC. When the 3T3-L1 pre-adipocytes had reached 100\% confluence, the medium was changed to $90 \%$ DMEM supplemented with $10 \%$ FBS, $1.0 \mu \mathrm{M}$ dexamethasone, 0.5 $\mathrm{mM}$ methylisobutylxanthine and $1.0 \mu \mathrm{g} / \mathrm{mL}$ bovine insulin (referred to as differentiation medium). After $48 \mathrm{~h}$ of culture in this medium, the medium was again changed to 90\% DMEM supplemented with $10 \%$ FBS and $1.0 \mu \mathrm{g} / \mathrm{mL}$ bovine insulin (referred to as maintenance medium). Adipocyte differentiation was determined by oil red $\mathrm{O}$ staining. Both pre-adipocytes and adipocytes were cultured in 6-well plates at $37^{\circ} \mathrm{C}$ in a humidified atmosphere consisting of $95 \%$ air and $5 \% \mathrm{CO}_{2}$.

\section{Cell proliferation}

The cells were seeded into 96-well plates at a density of at $1.0 \times 10^{4}$ cells/well and allowed to attach for $24 \mathrm{~h}$. The cells were treated with vehicle or with the indicated concentrations of BME diluted in complete media for 24,48 , and $72 \mathrm{~h}$. Cell proliferation was determined using MTS assay (Promega, 3580, Madison, WI, USA). The prolifera- 
tive activities were expressed as the relative percentage at the initial time.

\section{Oil-red $\mathrm{O}$ staining and triglyceride (TG) assay}

3T3-L1 pre-adipocytes were cultured and fully differentiated with and without BME during 6 days. The cells were washed twice with PBS and fixed with $10 \%$ formalin for 30 min. After fixation, they were washed with $60 \%$ isopropanol for $5 \mathrm{~min}$ and then stained with oil-red $\mathrm{O}$ working solution ( $1.5 \mathrm{mg} / \mathrm{mL}$ oil-red $\mathrm{O} / 60 \%$ isopropanol) for 15 min at RT. Then, they were washed with distilled water and photographed under a light microscope. Next, the TG levels were measured in cell lysates using Triglyceride Colorimetric Assay Kit (Cayman, Ann Arbor, MI, USA). Cells were washed twice with PBS then scraped and centrifuged at $100 \times \mathrm{g}$ for $5 \mathrm{~min}$. Cell pellets were lysed in standard diluent buffer and centrifuged at $10,000 \times \mathrm{g}$ for 10 min. The supernatant was collected and measured the TG.

\section{Western blot and protein quantification}

Cells and tissues were lysed in RIPA buffer (Thermo Fisher Scientific, Waltham, MA, USA). Total protein concentrations were determined using the BCA assay (PIERCE, Rockford, IL, USA). An equal volume of $4 \mathrm{X}$ SDS sample buffer was added, and the samples were boiled for $5 \mathrm{~min}$. Equivalent amounts of total protein $(10-30 \mu \mathrm{g})$ were separated by SDS-PAGE on $8 \%-12 \%$ polyacrylamide gel and then transferred to a nitrocellulose membrane. The membrane was blocked with $5 \%$ skim milk or $3 \%$ BSA in $0.1 \%$ Tween-20/Tris buffered saline (TBS-T). The membrane was incubated with SIRT1 (1:1,000,\#2493, Cell Signaling Technology, Beverly, MA, USA), PPAR $\gamma(1: 1,000, \# 2443$, Cell Signaling Technology), sterol regulatory element binding protein 1 (SREBP1) (1:1,000, sc-8984, Santa Cruz Biotechnology, Dallas, TX, USA), AMPK (1:1,000, \#2532, Cell Signaling Technology), p-AMPK (1:1,000, \#2535, Cell Signaling Technology), and $\beta$-actin $(1: 10,000$, A5441, Sigma,
St. Louis, MO, USA) primary antibodies overnight at $4{ }^{\circ} \mathrm{C}$ and secondary antibodies were incubated for $1 \mathrm{~h}$ at RT. Labeled proteins were detected by ECL (Thermo Fisher Scientific) using LAS 4000 (Fujifilm, Tokyo, Japan).

\section{HFD-induced obese mice}

Basically, animal model was same as a previous study (Yoon et al., 2017). Five-week-old male C57BL/6J mice were purchased from Central Lab Animal Inc. (Seoul, Korea). The $\mathrm{C} 57 \mathrm{BL} / 6 \mathrm{~J}$ mice were randomly divided into four groups $(n=8-12)$. The first group was fed a normal diet (ND), the second was fed a HFD, and the other two groups were fed a HFD supplemented with $250 \mathrm{mg}$ BME/kg BW (BME 250) and $500 \mathrm{mg} \mathrm{BME} / \mathrm{kg}$ BW (BME 500), respectively. The ND group was fed a chow diet (10\% kcal from fat, New Brunswick, NJ, USA, Research Diets; D12450B) or a HFD (45\% kcal from fat, New Brunswick, NJ, USA, Research Diets; D12451) for 12 weeks and then fed HFD supplemented with BME $250(250 \mathrm{mg} / \mathrm{kg}$ body weight/ day) or $500(500 \mathrm{mg} / \mathrm{kg}$ body weight/day) for 12 weeks. The animals were housed in a temperature-controlled environment with a $12 \mathrm{~h}$ light/dark cycle throughout the 12 week experimental period. Food intake and body weight were measured weekly. At the end of the experimental period, animals were anesthetized with zoletil $(5 \mathrm{mg} / \mathrm{kg}$, Virbac Laboratories, Carros, France) and perfused with 4\% paraformaldehyde solution in $0.1 \mathrm{M}$ phosphate-buffered saline (NBP) through the left ventricle. The white adipose tissues (WATs; epididymal fat, mesentery fat, perierenal fat) were removed and weighed. Portions of WATs were immersed in 4\% NBP for histological inspection and other portions were frozen immediately in liquid nitrogen and stored at $-80^{\circ} \mathrm{C}$ for protein samples. All animal procedures adhered to the Animal Care and Use Guidelines of Gyeongsang National University. The experimental protocol was approved by the Institutional Animal Care and Use Committee of Gyeongsang National University (Jinju, Korea, GNU-140818-M0034). 


\section{Hematoxylin and eosin (H\&E) staining}

Fixed WATs in 4\% NBP were dehydrated though a graded series of ethanol $(70 \%, 80 \%, 90 \%, 95 \%$, and $100 \%$ absolute ethanol) for $2 \mathrm{~h}$ per concentration, cleared in two changes of xylene for $2 \mathrm{~h}$ per change and impregnated using two changes of molten paraffin wax for $2 \mathrm{~h}$ per change in a Leica tissue processor (TP 1020, Leica, Wetzlar, Germany). The embedded tissue was sectioned at a thickness of $5 \mu \mathrm{m}$ with a microtome (RM2235, Leica) and subjected to H\&E staining. All stained tissue sections were imaged using a virtual slide microscope (BX61, Olympus, Tokyo, Japan) at $\times 20$ magnification with Olyvia software (Olympus).

\section{Statistical analysis}

The data are expressed as the mean and the standard error of the mean (means \pm SEM). The differences among the groups were analyzed by one-way analyses of variance (ANOVA), followed by Tukey's HSD test in the GraphPad Prism 5 software (GraphPad Software Inc., La Jolla, CA, USA).

\section{RESULTS}

\section{Effects of BME on cell proliferation}

The proliferation assay was performed to assess the effect of the BME on 3T3-L1 cell proliferation. BME showed no significant cytotoxicity at 125,250 , or 500 $\mu \mathrm{g} / \mathrm{mL}$ after 24,48 , and $72 \mathrm{~h}$ treatments (Fig. 1).

\section{BME inhibited the differentiation of 3T3-L1 cells}

To study the effects of BME on adipocyte differentiation, 3T3-L1 pre-adipocytes were differentiated into mature adipocytes for 6 days in the presence of $500 \mu \mathrm{g} / \mathrm{mL}$ BME and the accumulated intracellular lipids were detected by oil-red $\mathrm{O}$ staining. BME $500 \mu \mathrm{g} / \mathrm{mL}$ significantly suppressed lipid drop formation compared with untreated differentiated 3T3-L1 cells (Fig. 2A). The intracellular TG

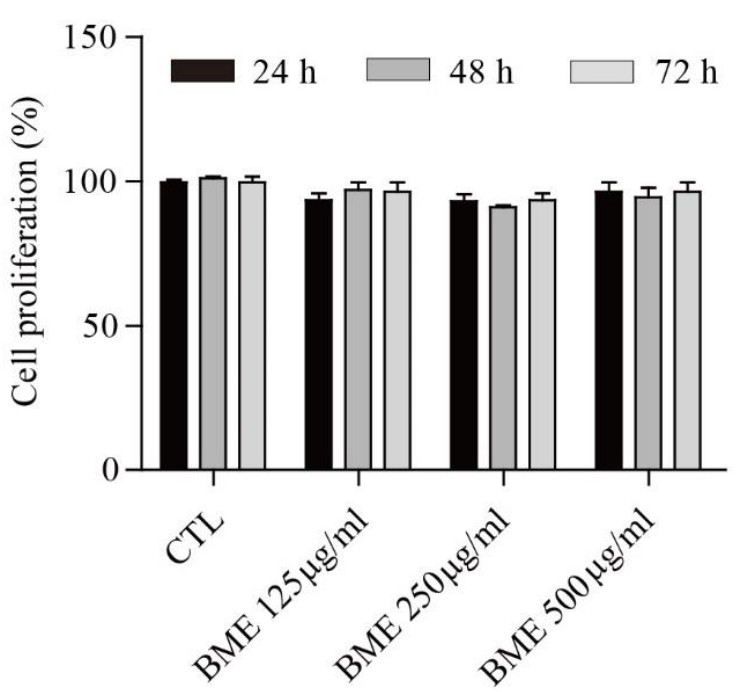

Fig. 1. Effects of BME on 3T3-L1 cells. The effect of BME on 3T3-L1 cell proliferation was measured by the MTS assay. 3T3-L1 cells were treated with the indicated concentrations of BME $(500 \mu \mathrm{g} / \mathrm{mL})$ for 24,48 , and $72 \mathrm{~h}$. The bar graphs show the mean \pm SEM of 3 independent experiments (n.s. compared with the DMSO-treated control). BME, ethanol extract of bitter melon.

was also reduced in the BME-treated cells (Fig. 2B). The data suggest that BME inhibits 3T3-L1 cells differentiation into adipocyte.

3. BME inhibited the expression of adipogenic genes through activated SIRT1 and AMPK in 3T3-L1 adipocytes

To elucidate the effects of BME on the activation of SIRT1 and AMPK in differentiated 3T3-L1 cells, western blotting was used. BME increased SIRT1 expression and decreased PPAR $\gamma$ and SREBP1 expression (Fig. 3A). Similarly, the BME increased p-AMPK without affecting the protein level of AMPK (Fig. 3B).

\section{BME ameliorated HFD-induced obesity}

The body weight gain in the HFD group was significantly greater than that in the ND group. Notably, the body weight gain in both the BME 250 and 500 groups 
(A)

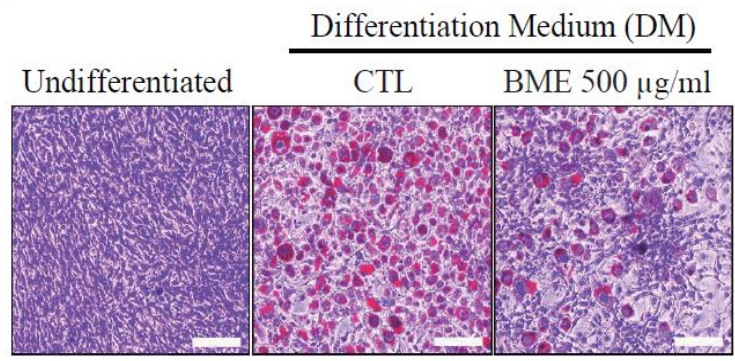

(B)

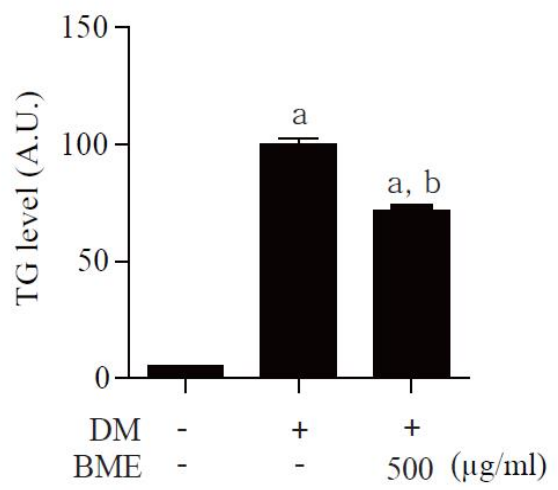

Fig. 2. Inhibitory effect of BME on lipid accumulation in 3T3-L1 adipocytes. (A) The effect of BME on lipid droplet formation was measured by oil-red $\mathrm{O}$ staining. 3T3-L1 pre-adipocytes were differentiated into adipocytes in the presence of BME $(500 \mu \mathrm{g} / \mathrm{mL})$ for 6 days. (B) Quantification of triglyceride content. The bar graphs show the mean \pm SEM of 3 independent experiments a $p<0.001$ vs. DM- \& BME-, ${ }^{\mathrm{b}} p<0.001$ vs. $\mathrm{DM}+\& \mathrm{BME}-$. Scale bar represents $200 \mu \mathrm{m}$. BME, ethanol extract of bitter melon.

were significantly lower than those in the HFD group (Fig. 4A). No significant difference in food intake was observed among the ND, HFD, BME 250 and 500 groups (data not shown), indicating that the reduction in body weight gain in the BME-supplemented HFD groups was not due to reduced caloric intake. To determine whether the reduced body weight gain was related to decreased fat accumulation, WATs were dissected and weighed. The weights of WATs were greater in the HFD group compared to the ND group, but the HFD supplemented with BME 500 group showed reduced increases in WAT weight and size (Fig.
$4 \mathrm{~B}, \mathrm{C})$, indicating that BME ameliorated obesity in a HFD supplemented with BME due to reduced adiposity in WAT. A histological analysis of the WATs revealed smaller adipocytes in the HFD supplemented with BME 500 group than in the HFD group (Fig. 4D), further demonstrating that the reduced body weight gain was due to decreased fat accumulation in the adipocytes.

\section{BME suppressed the activated SIRT1 in HFD-} induced obese mice

To determine whether reduced adiposity was associated with SIRT1 activation, we analyzed the expression of SIRT1 in epididymal adipose tissue isolated from the HFD group and from the BME 250 and 500 groups. The expression of SIRT1 significantly increased in the BME 250 and 500 groups compared with the HFD group. The expressions of SIRT1 target genes, PPAR $\gamma$ and SREBP1, decreased in the BME 250 and 500 groups compare with HFD group (Fig. 5). These data are consistent with the results obtained from 3T3-L1 adipocytes and suggest that the anti-obesity effect of BME is based on the activation of SIRT1, which inhibits adipogenesis in vivo and in vitro.

\section{DISCUSSION}

Among the several extraction methods, ethanol extraction improved the highest inhibitory activities of $\alpha$ glucosidase and pancreatic lipase of BME (Moon et al., 2015). In many studies, BME has been reported to have anti-obesity effects in both rodents and humans. Bitter melon $(0.75 \%$ of diet $)$ supplementation significantly prevented body weight gain and visceral fat mass accumulation in rats fed a HFD. This weight reduction may be a result of increased fatty acid oxidation, which ultimately facilitates weight reduction (Chen \& $\mathrm{Li}, 2005$ ). In another study, bitter melon significantly decreased the weights of epididymal WAT, visceral fat, and adipose leptin and resistin mRNA levels in C57BL/6J mice fed a HFD (Shih et al., 
(A)
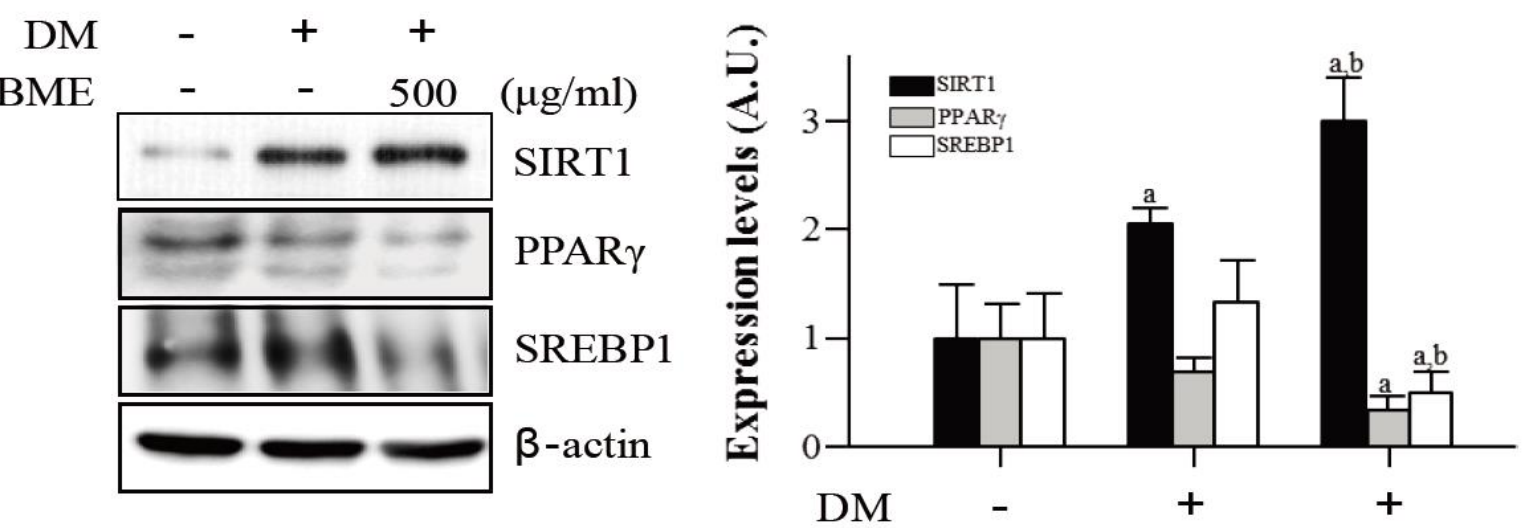

(B)
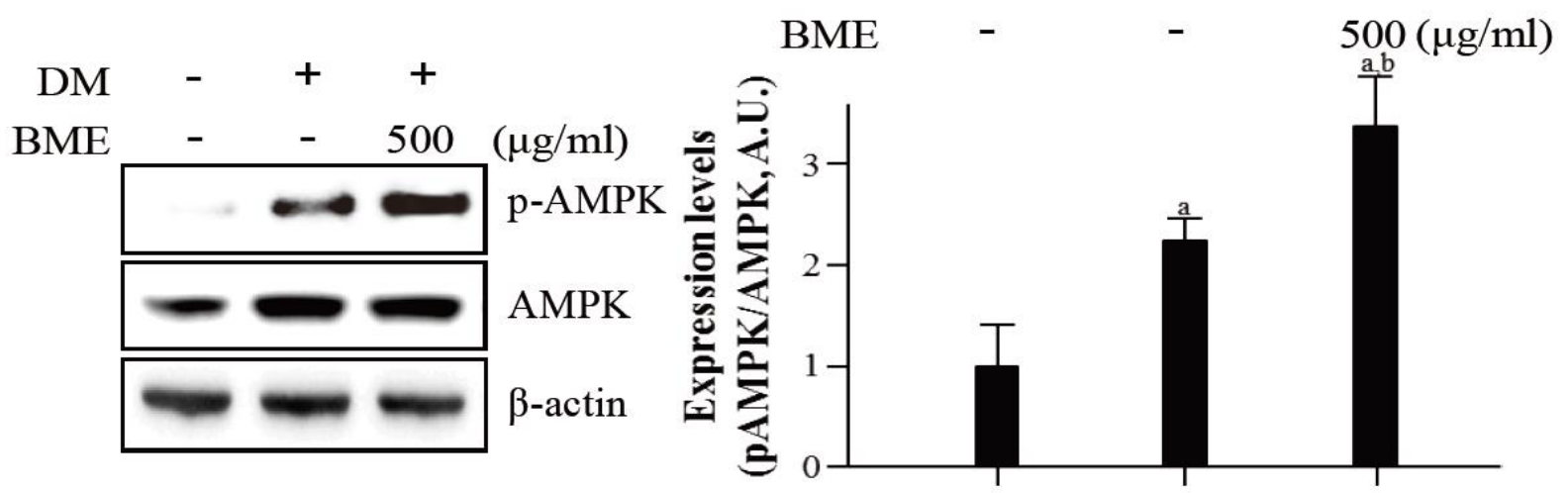

Fig. 3. BME activated SIRT1 and AMPK in differentiated 3T3-L1 cells. 3T3-L1 pre-adipocytes were differentiated into adipocytes in the presence of BME for 6 days. The protein expressions of (A) SIRT1, PPAR $\gamma$, SREBP1 and (B) pAMPK were evaluated by western blotting. HFD was used as the control, and $\beta$-actin was used as the loading control. The bar graphs show the mean \pm SEM of 3 independent experiments ${ }^{\mathrm{a}} p<0.01$ vs. DM- \& BME-, ${ }^{\mathrm{b}} p<0.01$ vs. $\mathrm{DM}+\& \mathrm{BME}-$. BME, ethanol extract of bitter melon; SIRT1, Sirtuin 1; AMPK, AMP-activated protein kinase; PPAR $\gamma$, peroxisome proliferator-activated receptor $\gamma$; HFD, high-fat diet.

2008). A recent study also showed that BME seed oil supplementation reduced body weight and fat mass in mice fed a HFD (Chen et al., 2012).

The improved anti-obesity effects of BME demonstrate that the polyphenol-extracted active component of bitter melon remains more stable in ethanol extract than in water extract. The BME show influence over pancreatic beta cells in streptozotocin-induced type 2 diabetic rats (Hafizur et al., 2011). Therefore, we need anticipatory and regulatory gene analyses of the anti-obesity effect of BME.

The activation of SIRT1 has been proposed as a therapeutic target for treating obesity and related metabolic disorders (Mouchiroud et al., 2013). In adipose tissue, SIRT1 regulates lipolysis and inhibits inflammation by inhibiting PPAR $\gamma$ and NF- $\kappa$ B activity (Picard et al., 2004; Pfluger et al., 2008; Mayoral et al., 2015). Another regulator, AMPK, is known to stimulate energy-generating pathways such as fatty acid oxidation and inhibit energy-consuming pathways such as lipogenesis by directly phosphorylating the key metabolic enzymes and subsequently regulating gene expression (Srivastava et al., 2012).

PPAR $\gamma$ is a critical transcription factor in adipocyte differentiation that stimulates the expression of the genes necessary for adipogenesis. SIRT1 has been shown to repress PPAR $\gamma$ by docking to the negative cofactors of the nuclear receptor and subsequently down regulating certain 
(A)

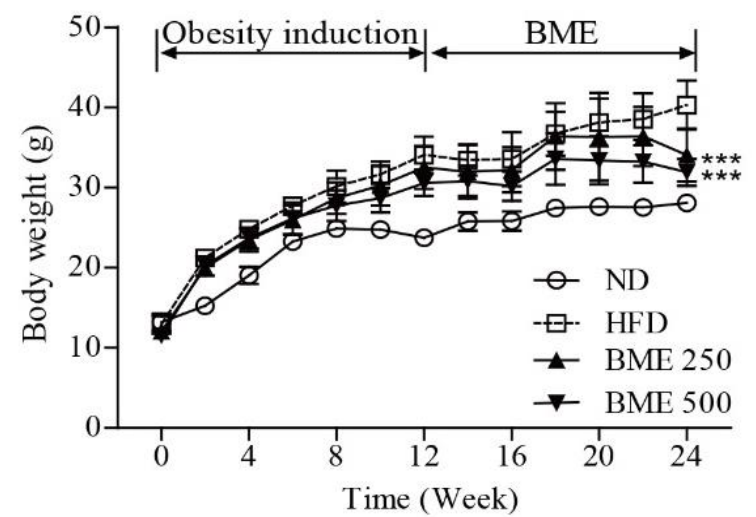

(C)

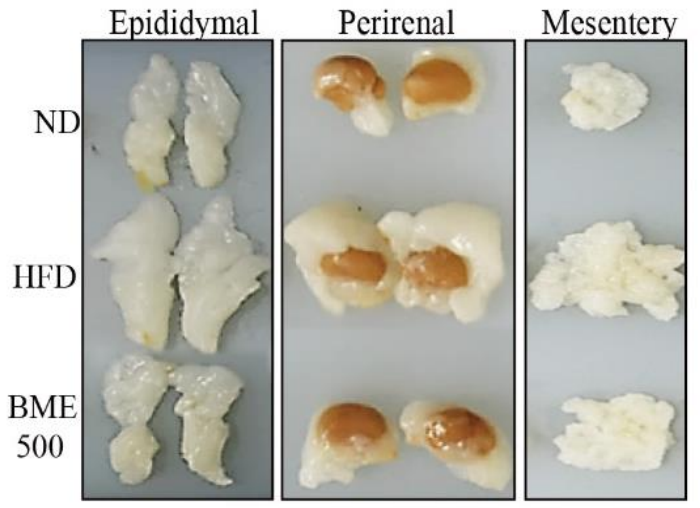

(B)

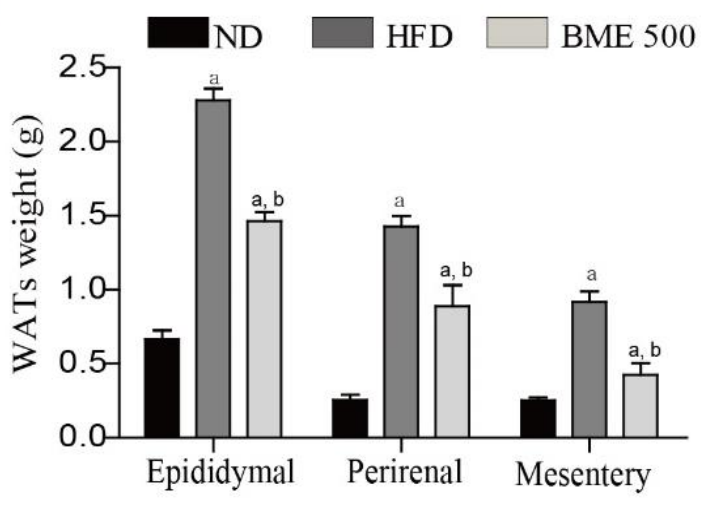

(D)

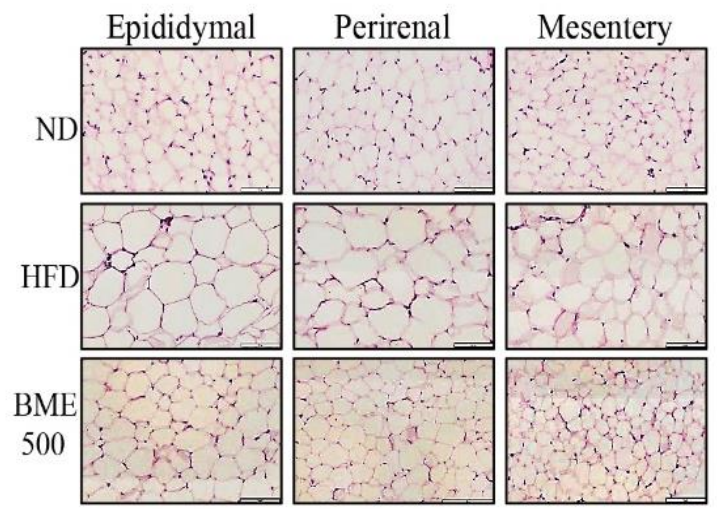

Fig. 4. Effect of BME on anti-obesity activity in HFD-induced obese mice. HFD-induced obese mice were supplemented with BME for 12 weeks. (A) Body weight was measured with 2 weeks interval for 24 weeks. (B) WATs (epididymal fat, perirenal fat, mesentery fat) weights, (C) Images of WATs, (D) H\&E-stained images of WATs samples from the ND, HFD, BME 500 groups. The bar graphs show the mean \pm SEM of $4-8$ individual animals. ${ }^{a} p<0.001$ vs. ND, ${ }^{b} p<0.001$ vs. HFD. Scale bar represents $100 \mu \mathrm{m}$. HFD, high-fat diet. BME, ethanol extract of bitter melon; WAT, white adipose tissue.

genes (Picard et al., 2004). Moreover, in differentiated adipose cells, the upregulation of SIRT1 leads to decreased fat storage and increased lipolysis (Baur et al., 2006; Lagouge et al., 2006). BME activated SIRT1 and reduced target genes such as PPAR $\gamma$ and SREBP1 in both preadipocytes and fully differentiated adipocytes. The activation of SIRT1 led to the suppression of 3T3-L1 differentiation, which may have prevented weight gain in the HFDinduced obese mice. The activation of SIRT1 and its target genes was also observed in the epididymal adipose tissue of the HFD mice supplemented with BME. Therefore, the anti-obesity effect of BME can be ascribed partially to the activation of SIRT1. To elucidate the anti-obesity mechanism of BME further, we examined AMPK activation because AMPK is known to be involved in the regulation of adipogenesis and the activation of AMPK suppresses adipogenesis (Han et al., 2011). AMPK may play a beneficial role in the prevention of metabolic diseases, including type 2 diabetes, obesity and cancer. It is also involved in the maintenance of lipid and cholesterol homeostasis and stimulates the oxidation of fatty acids in the mitochondria for lipid utilization (Hardie, 2008). In the present study, 

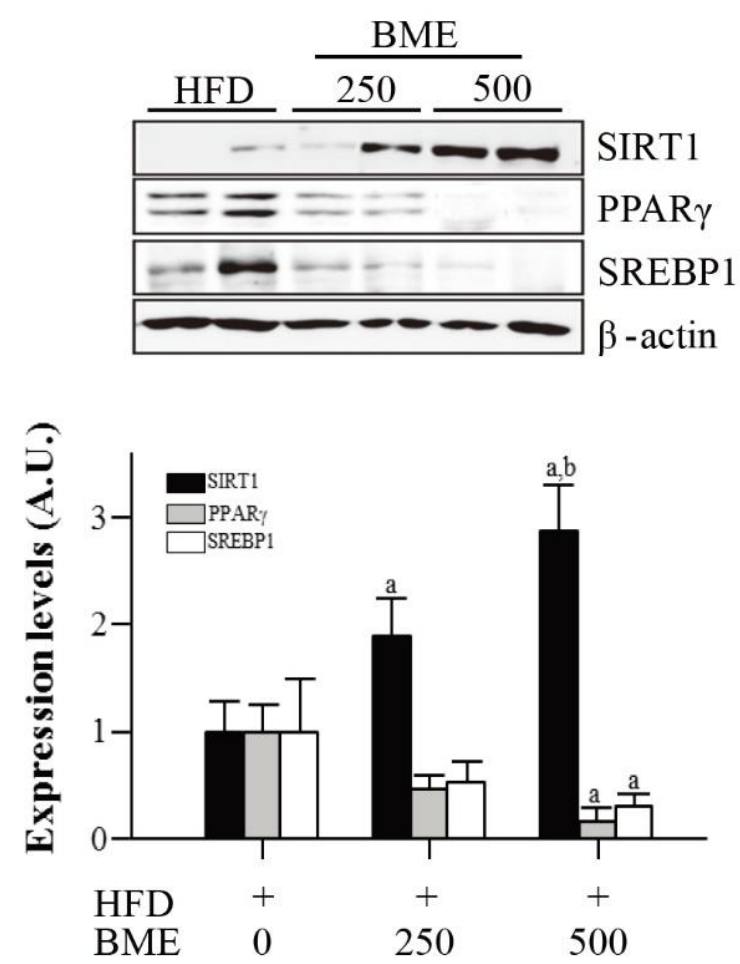

Fig. 5. BME activated SIRT1 in epididymal adipose tissue. The protein expressions of SIRT1, PPAR $\gamma$ and SREBP1 were evaluated by western blotting. Upper panel shows the representative photos of 4 individual animals. HFD was used as the control, and $\beta$-actin was used as the loading control. Lower bar graph shows quantification of western bands normalized with $\beta$-actin. ${ }^{a} p<0.05$ vs. HFD only group, ${ }^{\mathrm{b}} p<0.05$ vs. HFD + BME 250 group. HFD, high-fat diet. BME, ethanol extract of bitter melon; SIRT1, Sirtuin 1; PPAR $\gamma$, peroxisome proliferatoractivated receptor $\gamma$; SREBP1, sterol regulatory element binding protein 1 .

BME stimulated AMPK phosphorylation both in pre-adipocytes and in fully differentiated adipocytes. AMPK activation also suppresses the expressions of PPAR $\gamma$, FAS, and aP2 in 3T3-L1 adipocytes and inhibits the adipogenesis of 3T3-L1 cells (Vingtdeux et al., 2011). Here, we found that BME suppressed the expression of PPAR $\gamma$. Therefore, the suppression of PPAR $\gamma$ expression via BME treatment may be due to AMPK activation. Together, these results suggest that the activation of AMPK is also involved in the BME- mediated anti-obesity effect. In conclusion, BME may be a useful natural anti-obesity agent that reduces the risk for metabolic disorders.

\section{ACKNOWLEDGEMENTS}

This work was supported by the Cooperative Research Program for Agriculture Science and Technology Development (Project no. PJ00010003022016) of the Rural Development Administration, Korea.

\section{REFERENCES}

Baur JA, Pearson KJ, Price NL, Jamieson HA, Lerin C, Kalra A, Prabhu VV, Allard JS, Lopez-Lluch G, Lewis K, Pistell PJ, Poosala S, Becker KG, Boss O, Gwinn D, Wang M, Ramaswamy S, Fishbein KW, Spencer RG, Lakatta EG, Le Couteur D, Shaw RJ, Navas P, Puigserver P, Ingram DK, de Cabo R, Sinclair DA (2006) Resveratrol improves health and survival of mice on a high-calorie diet. Nature 444:337-342.

Chang HC, Yang HC, Chang HY, Yeh CJ, Chen HH, Huang KC, Pan WH (2017) Morbid obesity in Taiwan: Prevalence, trends, associated social demographics, and lifestyle factors. PLOS ONE 12:e0169577.

Chen PH, Chen GC, Yang MF, Hsieh CH, Chuang SH, Yang HL, Kuo YH, Chyuan JH, Chao PM (2012) Bitter melon seed oil-attenuated body fat accumulation in diet-induced obese mice is associated with cAMPdependent protein kinase activation and cell death in white adipose tissue. J Nutr 142:1197-1204.

Chen Q, Li ET (2005) Reduced adiposity in bitter melon (Momordica charantia) fed rats is associated with lower tissue triglyceride and higher plasma catecholamines. Br J Nutr 93:747-754.

Fuangchan A, Sonthisombat P, Seubnukarn T, Chanouan R, Chotchaisuwat P, Sirigulsatien V, Ingkaninan K, Plianbangchang P, Haines ST (2011) Hypoglycemic effect 
of bitter melon compared with metformin in newly diagnosed type 2 diabetes patients. J Ethnopharmacol 134:422-428.

Graf BL, Raskin I, Cefalu WT, Ribnicky DM (2010) Plantderived therapeutics for the treatment of metabolic syndrome. Curr Opin Investig Drugs 11:1107-1115.

Hafizur RM, Kabir N, Chishti S (2011) Modulation of pancreatic beta-cells in neonatallystreptozotocin-induced type 2 diabetic rats by the ethanolic extract of Momordica charantia fruit pulp. Nat Prod Res 25:353367.

Han CY, Ki SH, Kim YW, Noh K, Lee DY, Kang B, Ryu JH, Jeon R, Kim EH, Hwang SJ, Kim SG (2011) Ajoene, a stable garlic by-product, inhibits high fat diet-induced hepatic steatosis and oxidative injury through LKB1-dependent AMPK activation. Antioxid Redox Signal 14:187-202.

Han TS, Lean ME (2016) A clinical perspective of obesity, metabolic syndrome and cardiovascular disease. JRSM Cardiovasc Dis 5:2048004016633371.

Hardie DG (2008) AMPK: A key regulator of energy balance in the single cell and the whole organism. Int $\mathrm{J}$ Obes (Lond) 32:S7-S12.

Hasani-Ranjbar S, Jouyandeh Z, Abdollahi M (2013) A systematic review of anti-obesity medicinal plants: An update. J Diabetes Metab Disord 12:28.

Jung UJ, Choi MS (2014) Obesity and its metabolic complications: The role of adipokines and the relationship between obesity, inflammation, insulin resistance, dyslipidemia and nonalcoholic fatty liver disease. Int $\mathrm{J}$ Mol Sci 15:6184-6223.

Keller KB, Lemberg L (2003) Obesity and the metabolic syndrome. Am J Crit Care 12:167-170.

Kim GS, Park HJ, Woo JH, Kim MK, Koh PO, Min W, Ko YG, Kim CH, Won CK, Cho JH (2012) Citrus aurantium flavonoids inhibit adipogenesis through the Akt signaling pathway in 3T3-L1 cells. BMC Complement Altern Med 12:31.
Kopelman PG (2000) Obesity as a medical problem. Nature 404:635-643.

Lagouge M, Argmann C, Gerhart-Hines Z, Meziane H, Lerin C, Daussin F, Messadeq N, Milne J, Lambert P, Elliott P, Geny B, Laakso M, Puigserver P, Auwerx J (2006) Resveratrol improves mitochondrial function and protects against metabolic disease by activating SIRT1 and PGC-1alpha. Cell 127:1109-1122.

Mayoral R, Osborn O, McNelis J, Johnson AM, Oh DY, Izquierdo CL, Chung $\mathrm{H}$, Li P, Traves PG, Bandyopadhyay G, Pessentheiner AR, Ofrecio JM, Cook JR, Qiang L, Accili D, Olefsky JM (2015) Adipocyte SIRT1 knockout promotes PPARgamma activity, adipogenesis and insulin sensitivity in chronic-HFD and obesity. Mol Metab 4:378-391.

Moon JH, Choi DW, Kim SE, Seomoon JH, Hong SY, Kim HK, Cho KM, Song J, Kang SS, Kim KH, Kwon OK (2015) Comparison of biological activities of ethanol extracts of unripe fruit of bitter melon (Momordica charantia L.) cultivated in Hamyang, Korea. J Korean Soc Food Sci Nutr 44:1637-1644.

Mouchiroud L, Houtkooper RH, Auwerx J (2013) NAD( ${ }^{+}$) metabolism: A therapeutic target for age-related metabolic disease. Crit Rev Biochem Mol Biol 48:397-408.

Park HJ, Chung BY, Lee MK, Song Y, Lee SS, Chu GM, Kang SN, Song YM, Kim GS, Cho JH (2012) Centipede grass exerts anti-adipogenic activity through inhibition of $\mathrm{C} / \mathrm{EBPbeta}$, C/EBPalpha, and PPARgamma expression and the AKT signaling pathway in 3T3-L1 adipocytes. BMC Complement Altern Med 12:230.

Pfluger PT, Herranz D, Velasco-Miguel S, Serrano M, Tschop MH (2008) Sirt1 protects against high-fat dietinduced metabolic damage. Proc Natl Acad Sci USA 105:9793-9798.

Picard F, Kurtev M, Chung N, Topark-Ngarm A, Senawong T, Machado De Oliveira R, Leid M, McBurney MW, Guarente L (2004) Sirt1 promotes fat mobilization in white adipocytes by repressing PPAR-gamma. Nature 
429:771-776.

Pi-Sunyer X (2009) The medical risks of obesity. Postgrad Med 121:21-33.

Ray RB, Raychoudhuri A, Steele R, Nerurkar P (2010)

Bitter melon (Momordica charantia) extract inhibits breast cancer cell proliferation by modulating cell cycle regulatory genes and promotes apoptosis. Cancer Res 70:1925-1931.

Ru P, Steele R, Nerurkar PV, Phillips N, Ray RB (2011) Bitter melon extract impairs prostate cancer cell-cycle progression and delays prostatic intraepithelial neoplasia in TRAMP model. Cancer Prev Res (Phila) 4: 2122-2130.

Shih CC, Lin CH, Lin WL (2008) Effects of Momordica charantia on insulin resistance and visceral obesity in mice on high-fat diet. Diabetes Res Clin Pract 81:134143.

Srivastava RA, Pinkosky SL, Filippov S, Hanselman JC, Cramer CT, Newton RS (2012) AMP-activated protein kinase: An emerging drug target to regulate imbalances in lipid and carbohydrate metabolism to treat cardiometabolic diseases. J Lipid Res 53:2490-2514.

Vingtdeux V, Chandakkar P, Zhao H, Davies P, Marambaud P (2011) Small-molecule activators of AMPactivated protein kinase (AMPK), RSVA314 and RSVA405, inhibit adipogenesis. Mol Med 17:10221030.

Yang JW, Kim SS (2015) GinsenosideRc promotes antiadipogenic activity on 3T3-L1 adipocytes by downregulating C/EBP alpha and PPARgamma. Molecules 20:1293-1303.

Ye X, Li M, Hou T, Gao T, Zhu WG, Yang Y (2017) Sirtuins in glucose and lipid metabolism. Oncotarget 8:1845-1859.

Yoon NA, Park J, Lee J, Jeong JY, Kim HK, Lee HS, Hwang IG, Roh GS, Kim HJ, Cho GJ, Choi WS, Lee DH, Kang SS (2017) Anti-diabetic effects of ethanol extract from bitter melon in mice fed a high-fat diet. Dev Reprod 21:259-267. 